\title{
Insulin resistance and reduced brain glucose metabolism in the aetiology of Alzheimer's disease
}

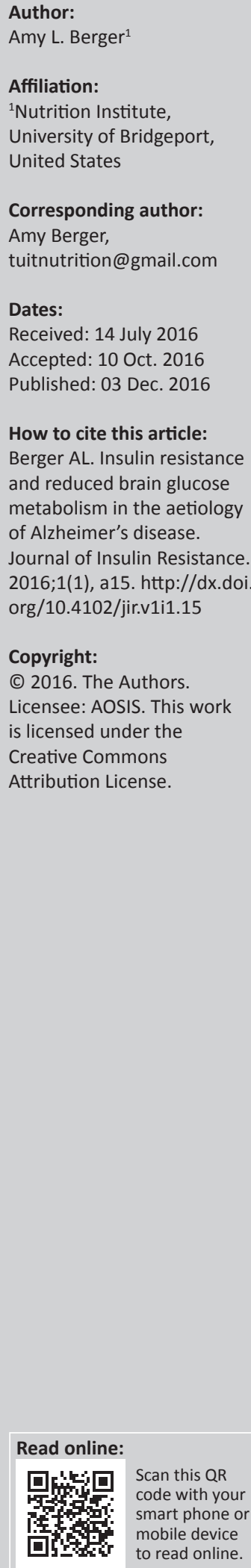

Significant epidemiological and clinical evidence has emerged that suggests Alzheimer's disease (AD) can be added to the list of chronic illnesses that are primarily caused by modern diets and lifestyles at odds with human physiology. High intakes of refined carbohydrates, insufficient physical activity, suboptimal sleep quantity and quality, and other factors that may contribute to insulin resistance combine to create a perfect storm of glycation and oxidative stress in the brain. Specific neurons lose the ability to metabolise and harness energy from glucose, ultimately resulting in neuronal degeneration and death. Simultaneously, chronic peripheral hyperinsulinaemia prevents ketogenesis, thus depriving struggling neurons of a highly efficient alternative fuel substrate. The intimate association between type 2 diabetes and AD suggests that they have common underlying causes, namely insulin resistance and perturbed glucose metabolism. Preclinical evidence of AD is detectable decades before overt symptoms appear, indicating that AD progresses over time, with observable signs manifesting only after the brain's compensatory mechanisms have failed and widespread neuronal atrophy begins to interfere with cognition and performance of daily life tasks. That dietary and environmental triggers play pivotal roles in causing AD suggests that nutrition and lifestylebased interventions may hold the key to ameliorating or preventing this debilitating condition for which conventional pharmaceutical treatments are largely ineffective. Results from smallscale clinical studies indicate that dietary and lifestyle strategies may be effective for reversing dementia and cognitive impairment. Increased research efforts should be dedicated towards this promising avenue in the future.

\section{Introduction}

Few modern degenerative illnesses incite as much fear as Alzheimer's disease (AD). It is difficult when one's physical body loses the strength and mobility afforded in youth, but cognitive decline - memory loss, deterioration of cognition, and disturbing behavioural changes - incites even greater concern, as individuals speculate about how they will be affected, personally, and what the ramifications will be of becoming a burden on their families.

Too often, newly diagnosed patients are told that AD is a mystery, and that they are powerless to slow or stop its course: the biochemical and physiological mechanisms behind the pathology and progression of this condition remain elusive, and, as a result, there are currently no effective treatment protocols. Patients and their families are provided few recommendations beyond getting their finances and personal affairs in order in preparation for the inevitable decline. Pharmaceutical drugs developed to date have been ineffective, as they typically aim to treat symptoms, rather than targeting and correcting the underlying causes. In fact, some pharmaceutical agents designed to target biochemical pathways tentatively implicated in disease pathogenesis and progression have actually worsened disease progression. ${ }^{1}$ This symptom-oriented approach has failed patients and their caregivers for too long. It is time to reorient AD research, treatment and potential prevention strategies towards what a large and continually growing body of scientific evidence suggests is the main underlying disturbance in the Alzheimer's brain: the deterioration and death of hippocampal neurons subsequent to their loss of capacity to harness energy from glucose.

Economic costs associated with Alzheimer's disease and other forms of dementia are staggering. In the United States alone, the financial toll of these conditions was $\$ 225$ billion in 2015, with projections for this figure to exceed a trillion dollars by $2050 .^{2}$ This enormous economic tally includes government healthcare spending as well as increased costs incurred by individual families, among whom people may need to abandon their professions to assume full-time caregiving roles for afflicted loved ones, and who incur increased healthcare costs of their own approaching $\$ 10$ billion - because of the physical and psychological tolls caregiving exacts. 
Approximately 5.3 million Americans are living with $\mathrm{AD}$, with this number predicted to reach 7.1 million by 2025, and a staggering 13.8 million by 2050 . Alzheimer's is the sixth leading cause of death in the United States, and while deaths due to other leading causes of mortality - such as heart disease and some forms of cancer - have decreased in recent years, deaths attributed to AD have increased by $71 \%$ since 2000.

According to the Alzheimer's Association, 'Alzheimer's is the only disease among the top 10 causes of death in America that cannot be prevented, cured or even slowed'. ${ }^{2}$ Owing to the lack of effective treatments for this illness, a diagnosis of $\mathrm{AD}$ amounts to a death sentence. The financial burden affected families face is compounded by the helplessness and hopelessness that accompany such a diagnosis. However, viewing Alzheimer's disease as a metabolic disturbance, with a relatively clear aetiology and pathophysiology, suggests that there may be effective ways to prevent, delay and possibly reverse the progression of this dreaded disease. The scientific literature is replete with research referring to Alzheimer's disease as 'diabetes of the brain', or 'type 3 diabetes'.,4,5 There are profound connections between insulin resistance, hyperinsulinaemia and $\mathrm{AD}$, as well as other forms of cognitive decline, such as mild cognitive impairment, the precursor to AD). ${ }^{6,7,8,9,10,11,12,13,14}$ In fact, chronic hyperinsulinaemia is one of the primary risk factors for development of AD. ${ }^{15,16}$

\section{Alzheimer's disease as a metabolic condition}

Considering the strong links between hyperinsulinaemia/ insulin resistance (IR) and development of Alzheimer's disease, it is not surprising that type 2 diabetes (T2D) is a significant risk factor for AD. However, a diagnosis of T2D is not required for eventual progression to $\mathrm{AD}$, because $\mathrm{T} 2 \mathrm{D}$ does not cause AD. Rather, they may be thought of as 'physiological cousins' - conditions that result from the same underlying metabolic disturbances, but which have different outward manifestations in the body. One may be a diagnosed $\mathrm{T} 2$ diabetic and not develop $\mathrm{AD}$, and many $\mathrm{AD}$ patients are not diagnosed diabetics.

Diagnosis of T2D is prompted by abnormalities in blood glucose measurements - elevated fasting blood glucose (FBG), elevated haemoglobin A1c (HgbA1c), and an abnormal response to an oral glucose tolerance test (OGTT). Measurements of glycaemic control, however, fail to account for what is potentially a much more powerful and more insidious factor in the development of Alzheimer's disease: chronically elevated insulin. An array of OGTTs performed by Dr J. Kraft and colleagues - which were extended to 5-hours from the traditional 2-hours and also included insulin assays - indicated that several thousand individuals with normal measurements of glycaemic control were hyperinsulinaemic. ${ }^{17,18}$ The addition of insulin testing to the OGTT revealed IR and hyperinsulinaemia among patients whose glucose dynamics would have shown them falsely - to be metabolically healthy. And it is dysregulated insulin - specifically, hyperinsulinaemia/IR - rather than hyperglycaemia, that evidence indicates a causal role for in the pathology and progression of AD. Therefore, it cannot be assumed that individuals with normal blood glucose markers are not at risk for conditions related to metabolic derangement. In fact, the correlations between peripheral and brain insulin resistance, metabolic syndrome, and Alzheimer's disease are so profound that researchers have coined the phrase 'metabolic-cognitive syndrome' to underscore their common physiologic origins. . $^{1920,21,22}$

Clinically, Alzheimer's patients present with decreased cognitive function and lapses in memory that decline progressively and ultimately impact performance of everyday life tasks. Physiologically, AD is characterised by several physical hallmarks that can be measured or observed via biopsy, positron emission tomography (PET) scan, or upon autopsy. These include insoluble extracellular plaques made of beta-amyloid peptide $(A \beta)$; intracellular neurofibrillary tangles (NFTs), loss of hippocampal neurons; and a marked decline in the metabolism of glucose in regions of the brain associated with memory and learning. All of these changes can be logically explained as sequelae resulting from long-term dysregulation of insulin signalling and glucose energetics.

\section{Reduced cerebral glucose metabolism}

There is a significant link between Alzheimer's disease and impaired fuel metabolism in the brain, with disturbed cerebral glucose metabolism being an invariant pathophysiological feature of $\mathrm{AD} .^{23}$ The defining metabolic signature of $\mathrm{AD}$ is a decrease in the cerebral metabolic rate of glucose (CMRglu). This may be the primary underlying cause of neuronal degeneration and death: at its heart, AD is an energy crisis in the brain. It is the death of neurons via starvation, as they have lost the capacity to effectively harvest energy from glucose. Before overt cell death, however, affected neurons may degrade axons and dendrites in order to conserve energy for the purpose of protecting the viability of the cell body. The retraction of these projections results in compromised synapses and loss of communication between neurons, which may manifest as memory loss, behavioural abnormalities, and the other observable signs of mild cognitive impairment and AD. ${ }^{24}$ Some researchers have stated that the 'primary pathophysiological mechanism in the early stage of AD is synaptic dysfunction [...] based on impairment of glucose degradation' ${ }^{25}$

Reductions in CMRglu are observable via PET scan in individuals with genetic risk factors for AD as early as in their 30s. Compared to healthy, age-matched individuals, subjects aged 20-39 with a known genetic factor predisposing for Alzheimer's disease (possession of the $\varepsilon 4$ allele for the ApoE gene, discussed in a subsequent section) had 
abnormally low CMRglu in the posterior cingulate region, parietal and temporal regions, and prefrontal cortex approximately $8.0 \%-10.5 \%$ lower than in subjects without the increased genetic susceptibility. ${ }^{26,27}$ It is important to note that these subjects were cognitively normal; they showed no signs or symptoms of impaired cognitive function, despite measurements showing an already present reduction in glucose metabolism in brain regions associated with memory processing and learning. Brain glucose hypometabolism may be the earliest step in the pathology of $\mathrm{AD}$ - a kind of metabolic 'canary in the coalmine' that sets the stage for cognitive decline decades before overt signs and symptoms begin to appear.

There is no doubt that the severity of perturbed glucose metabolism in the brain predicts future cognitive decline and eventual development of full-blown $\mathrm{AD}$, with disease severity likely influenced by the extent of the reduction in CMRglu. The greater the reduction in an individual's CMRglu compared to age-matched individuals with normal cerebral glucose metabolism, the greater their risk for cognitive decline in the form of mild cognitive impairment or Alzheimer's disease, and the more rapidly such outcomes may occur. A longitudinal study using PET scans to measure CMRglu in subjects aged $50-80^{28}$ showed that those with the lowest hippocampal CMRglu at baseline experienced the most rapid development of overt AD. At baseline testing, hippocampal glucose metabolism in subjects who progressed from normal cognition to mild cognitive impairment was $15 \%$ below that of subjects who did not develop cognitive decline, with this already reduced rate of cerebral glucose metabolism declining further by $2.4 \%$ annually. The data are even more telling for subjects who progressed from normal cognition to full-blown Alzheimer's disease: among these individuals, CMRglu at baseline was $26 \%$ below that of people who did not develop $\mathrm{AD}$, and starting with that $26 \%$ reduction, the additional annual rate of decline in cerebral glucose metabolism was $4.4 \%$. These reductions in cerebral glucose metabolism are in stark contrast to the mere $0.8 \%$ annual rate of decline in CMRglu among subjects who had normal CMRglu at baseline and did not develop AD. Extrapolating backward indicates that a decline in the rate of cerebral glucose metabolism may start as early as 20 years before overt signs of impaired cognition become observable in afflicted individuals. Again, at baseline, despite an already decreased CMRglu in some subjects, all subjects were cognitively normal. This suggests that a starting point of reduced glucose utilisation in the brain and a stronger rate of continued decline might be one of the earliest triggering events in Alzheimer's disease. ${ }^{29}$ Compared to healthy controls, AD patients show up to $45 \%$ reductions in CMRglu via PET scan, with one study's authors claiming that this is 'the predominant abnormality' in AD. ${ }^{25}$ Because the reduction in CMRglu begins many years before an individual receives a diagnosis of Alzheimer's disease or mild cognitive impairment, and during this time the individual may either self-assess or be described by others as having healthy cognition (perhaps with occasional episodes of odd behaviour or forgetfulness that are considered 'normal'), it may be that the brain is able to compensate for the reduced cerebral glucose usage until such reduction has progressed to a point that is insurmountable.

\section{Peripheral hyperinsulinaemia, insulin in the brain, and beta- amyloid plaques}

It was believed for some time that insulin played little role in glucose metabolism in the brain, as the common brain glucose transporters - GLUT1 and GLUT3 - are noninsulinsensitive. However, it is now established that there are both insulin receptors and insulin-sensitive glucose transporters (GLUT4s) at and beyond the blood-brain barrier, and they are particularly abundant in brain regions involved in learning and memory, such as the hippocampus. ${ }^{30,31}$ It has yet to be elucidated for certain whether all insulin in the brain and central nervous system (CNS) is of peripheral origin or if the CNS synthesises at least some of its own insulin. It is certain, however, that brain insulin dynamics play a role in neurotransmission, cognition, and the regulation of hormones that control feeding behaviour and reproductive function. ${ }^{32}$

A noteworthy feature of $\mathrm{AD}$ is the combination of hyperinsulinism in the periphery with hypoinsulinism in the CNS. Patients with advanced AD show higher plasma but lower cerebrospinal fluid (CSF) insulin concentrations than healthy controls and subjects with mild cognitive impairment. Moreover, the ratio of CSF to plasma insulin levels was significantly lower in patients with advanced dementia, with the degree of difference correlating to dementia severity. ${ }^{33}$ These compartmentalised alterations in insulin concentration were observed in individuals who lacked the strongest currently known genetic risk factor for development of AD: homozygosity for the $\varepsilon-4$ allele of the apolipoprotein E gene (ApoE4). This suggests again that peripheral hyperinsulinaemia/IR is a significant risk factor for AD regardless of genotype. ${ }^{34}$ Improper cellular responses to insulin may be responsible for the decline in CMRglu, as well as the rampant glycation observed in post-mortem examinations of AD brains. Neurons that are unable to take up glucose would show a decline in the metabolism of this fuel substrate, and as glucose accumulates in the extracellular space and/or its early metabolites build up intracellularly, it would form advanced glycation end-products (AGEs), which would further impair proper synaptic transmission and neuronal communication. Similar to a reduction in the CMRglu, AGE accumulation is a byproduct of normal, healthy aging. However, as with the decline in glucose utilisation, AGE formation occurs more quickly and to a greater degree in AD patients than in healthy individuals. AD brains show more AGEs than those of healthy, agematched controls, and this glycation contributes to otherwise soluble amyloid proteins becoming insoluble. ${ }^{35}$

Perturbed peripheral and central insulin dynamics likely underlie the second most well-recognised feature of 
Alzheimer's disease, after the reduced CMRglu: the extracellular accumulation of insoluble plaques consisting of beta-amyloid peptide. $A \beta$ results from the normal cleavage of the amyloid precursor protein, but its accumulation and aggregation into plaques represents one of the quintessential features of $\mathrm{AD} .{ }^{36} \mathrm{~A} \beta$ is detectable in healthy human brains, but its concentration is orders of magnitude larger in Alzheimer's-affected brains. ${ }^{37}$ This is noteworthy because lower concentrations of $A \beta$ tend to remain soluble and subject to degradation and clearance, while higher concentrations more readily aggregate into degradation-resistant insoluble plaques. ${ }^{38}$ Post-mortem sections from the brains of AD patients homozygous for ApoE4 have been shown to be so extensively riddled with $A \beta$ plaques that they can be distinguished from those of other AD patients without a microscope. ${ }^{39}$

The synthesis and secretion of amyloid precursor proteins are normal physiological processes. The formation of the insoluble plaques is what distinguishes an Alzheimer's brain from a healthy brain. However, there is no evidence that Alzheimer's patients secrete more $A \beta$ than healthy individuals; rather, in AD patients, these proteins are not properly degraded and cleared away. The enzyme responsible for degrading amyloid proteins in the brain is insulysin, also known as insulin degrading enzyme (IDE) - the same enzyme tasked with degrading insulin (as well as glucagon, atrial natriuretic peptide, and more). Peripheral hyperinsulinaemia - as seen in T2D, metabolic syndrome and other hyperinsulinaemic conditions associated with greater risk for AD - may induce a functional deficiency of IDE..$^{40}$ The affinity of IDE for insulin is much greater than that for $A \beta$, such that the presence of even small amounts of insulin completely inhibits the degradation of $A \beta \cdot{ }^{38,40}$ Thus, when IDE is saturated with insulin as a substrate, $A \beta$ is left to accumulate and form plaques.

Modern diets, high in evolutionarily novel refined, acellular carbohydrates, may be a contributing factor to the development of insulin resistance and, almost certainly, Alzheimer's disease. ${ }^{41,42,43}$ Additionally, inadequate sleep whether in quantity or quality - is another way in which the modern lifestyle may spur the progression of AD. Short sleep duration is associated with perturbations in insulin signalling and glucose metabolism such that insufficient sleep is now recognised as a risk factor for metabolic syndrome and type 2 diabetes. ${ }^{44,45,46}$ Alzheimer's patients often have disrupted circadian patterns. This may be a downstream effect of the condition, but it also likely precedes diagnosis and may be a contributing factor in the causative cascade for AD.${ }^{47}$ Human and animal studies indicate that $\mathrm{A} \beta$ exhibits a diurnal pattern: concentration rises during wakefulness and falls during sleep. ${ }^{48}$ The clearance of $A \beta$ is most active during sleep: PET scans of older adults show that, compared to those who report good sleep quality and quantity, those with self-reported poor sleep quality and short sleep duration have greater $A \beta$ burden and tau hyperphosphorylation (another physiological hallmark of AD), as do individuals with obstructive sleep apnea, compared to healthy controls. ${ }^{49,50}$ Researchers have yet to unravel the precise reasons underlying the invariant and absolute necessity for sleep across all observed animal species, but it seems that one of the crucial processes that occur during sleep is the clearance of neurotoxic metabolic wastes from the brain, including $A \beta{ }^{51}$ Thus, disrupted sleep represents a double assault upon brain health: elevated insulin levels may result in decreased activity of IDE for clearing $A \beta$, and shorter sleep duration may limit the amount of time during which $A \beta$ is most effectively cleared from the CNS.

A great deal of Alzheimer's disease research has focused on $\mathrm{A} \beta$ plaques and their role in potentiating the development of the condition. While it is true that glycated $A \beta$ plaques interfere with neurotransmission and may also be directly neurotoxic, pharmaceutical interventions targeting the synthesis of these plaques have failed to have a positive impact upon disease progression. One such agent was a $\gamma$-secretase inhibitor, intended to reduce activity of the enzyme that cleaves $A \beta$ from the amyloid precursor protein. Such an inhibitor would decrease production of $A \beta$, thereby limiting what is often considered a primary causative agent in AD. However, phase III clinical trials had to be halted because results were so striking against this treatment. Measures of cognition and ability to complete daily tasks for living were significantly worse for patients receiving the drug than the placebo. ${ }^{1}$

Viewing $\mathrm{AD}$ as a metabolic disorder, the accumulation of $\mathrm{A} \beta$ plaques may be seen as an effect, rather than a cause, of the condition. However, just as a fever (initially a protective mechanism of the immune system) spiking too high may create problems of its own, growing numbers of $A \beta$ plaques and their increasing density in a hyperglycaemic environment can initiate chain reactions of glycation and oxidation that serve to exacerbate impairment of neuronal fuel metabolism and cerebral ATP production, and precipitate cognitive decline. Nevertheless, targeting $A \beta$ plaques is a superficial approach that fails to address the root cause of cognitive decline: peripheral and brain insulin resistance and the resulting reduction in the brain's capacity to harness energy from glucose. It is unlikely that $\mathrm{A} \beta$ plaques are an initial causal factor in AD. They more logically result from glycation and functional inhibition of IDE due to peripheral hyperinsulinaemia. Moreover, effects of reduced glucose metabolism in the brain are observed long before evidence of plaque formation; in many cases, the latter occurs only relatively late in disease progression. This is not to suggest that the accumulation of glycated $A \beta$ plaques is not problematic; only that it is unlikely to be a primary causative agent in AD. A growing body of evidence suggests that focus on amyloid plaques as primary drivers of Alzheimer's pathogenesis distracts from other factors that align more strongly with multiple aspects of the aetiology and progression of the condition, such as metabolic abnormalities. ${ }^{52,53}$

\section{The role of ApoE4 genotype}

Finally, it is crucial to address the strongest and, to date, only known genetic risk factor for Alzheimer's disease: possession of one or two $\varepsilon 4$ (E4) alleles of the APOE gene (ApoE4). Possession of an $\varepsilon 4$ allele is so strongly correlated with AD that 
it has been called the 'susceptibility gene'. ${ }^{27}$ Heterozygotes for ApoE4 have a fivefold increased risk of developing AD, while homozygotes are estimated to have a staggering lifetime risk between $50 \%$ and $90 \% .{ }^{54}$ Despite this threatening genetic heritage, the ApoE4 allele is neither required nor sufficient for development of $\mathrm{AD}$ : $50 \%$ of people with $\mathrm{AD}$ are not $\mathrm{E} 4$ carriers, and many E4 homozygotes never develop the disease. Chronic hyperinsulinaemia/insulin resistance elevates risk independently of ApoE status, with a $43 \%$ increased risk for $\mathrm{AD}$ from hyperinsulinism alone, regardless of genotype. Among insulin-resistant individuals who were not diagnosed diabetics (normoglycaemic due to hyperinsulinaemia), the risk for $\mathrm{AD}$ was double that of those without IR. ${ }^{15}$ As hyperinsulinaemia occurs in approximately $40 \%$ of people over age 60 , it is not surprising to find a correlation between IR and a condition that preferentially strikes the aging. ${ }^{55}$

Although there are strong correlations between the ApoE4 genotype and $\mathrm{AD}$, the majority of $\mathrm{AD}$ patients are not ApoE4 carriers. One potential aggravating factor for the ApoE4 genotype is that ApoE4 homozygotes produce 50\% less hippocampal IDE compared to healthy controls, as well as AD patients who are not carriers of the $\varepsilon 4$ allele. ${ }^{36}$ Thus, these individuals may have reduced capacity to degrade $\mathrm{A} \beta$ peptides relative to other genotypes, which would explain, in part, the severity of AD observed in ApoE4 carriers. However, it has not been determined whether the ApoE4 gene causes reduced IDE synthesis. The ApoE4 gene and reduced IDE expression could both presumably be the result of an overall hunter-gatherer genotype poorly suited for the modern diet's evolutionarily discordant amount of refined carbohydrates. ${ }^{41,42,43,56}$

The distribution of the various ApoE gene isoforms is theorised to stem from human evolutionary migration patterns and the adoption of grain-based agriculture. ${ }^{57}$ Groups with the longest exposure to grain consumption have a lower E4 frequency suggesting that higher carbohydrate intakes may have selected against E4. ${ }^{41}$ The single amino acid substitutions that differentiate the three ApoE isoforms affect tendency for apolipoproteins to become glycated, as well as determine binding affinity to any number of enzymes and receptors, which is why the isoforms are associated with different trends in serum low-density lipoprotein (LDL), very low-density lipoprotein (VLDL) and triglyceride measurements, with ApoE4 being associated with hypertriglyceridaemia and elevated LDL - common findings in metabolic syndrome and insulin resistance. ${ }^{56,57,58}$ Preagriculturalists presumably would have derived more of their calories from fat, protein and high-fibre, lower-starch, vegetable-based carbohydrates as opposed to grains and acellular carbohydrates, and may therefore have had a lower requirement for both insulin and IDE. ${ }^{41,43,59,60}$

\section{A new direction for therapeutic intervention and treatment strategies}

The profound disturbances in glucose and insulin signalling that underlie Alzheimer's disease, coupled with the failure of pharmaceutical strategies aimed at reducing or preventing synthesis of $A \beta$ plaques to slow disease progression, suggests that the prevailing view of $\mathrm{AD}$ as a problem localised to the brain is myopic and self-limiting. Viewing AD instead as a metabolic abnormality - one involving systemic hyperinsulinaemia and insulin resistance affecting brain fuel metabolism, inflammation, glycation, and ultimately compromising neuronal energy generation - opens a vast array of promising therapeutic avenues. ${ }^{61,62,63}$ Rather than attempting to treat $\mathrm{AD}$ by attacking the symptoms piecemeal, dietary and lifestyle interventions aimed at addressing the fundamental root causes of physiological derailment may prove more effective. Moreover, strategies that help correct the underlying pathology may hold the key to not only delaying and possibly reversing $\mathrm{AD}$ and milder forms of cognitive decline, but perhaps, to preventing them altogether.

Clinical interventions employing this type of multipronged diet and lifestyle strategy have already yielded promising results. Among a small cohort of ten subjects with diagnosed Alzheimer's disease and mild cognitive impairment or subjective cognitive impairment, six had experienced cognitive decline severe enough to interfere with or require them to abandon their professions. ${ }^{64}$ After an intervention involving dietary carbohydrate reduction (via low-glycaemic or low-grain diets), micronutrient repletion, a daily 12-hour fast, increased sleep and physical exercise, supplementation with omega-3 fatty acids, antioxidants, and medium-chain triglycerides (the latter to serve as a source of ketones to fuel the brain), plus additional hormone optimisation and stress management techniques, all six experienced improvements significant enough for them to return to work, and all study subjects except one (with very advanced Alzheimer's at baseline) not only maintained their better cognition through at least 2.5 years of follow-up, but some had continual and marked improvement, as opposed to the inevitable decline such patients would typically expect to experience. The collective effects of these individual interventions likely resulted in reduced inflammation, glycation, and oxidative stress, increased mitochondrial biogenesis and brain-derived neurotrophic factor, elevated plasma ketones, and increased insulin sensitivity. $65,66,67,68,69$

The reduced presence of insulin in the CNS of Alzheimer's patients might lead one to speculate that exogenous insulin administration would be beneficial. Indeed, intranasal infusions of insulin have been shown to improve cognition in the short term in memory-impaired adults, but results were inconsistent across genotypes, with ApoE4 carriers experiencing decline in verbal memory. ${ }^{70,71}$ A short-term benefit may well be valuable, but ultimately, CNS insulin infusion fails to address the underlying systemic disturbances, which, if left unaddressed, will lead to further deterioration of cognitive function. A similar approach that may be beneficial for the short term, but which ultimately allows AD to progress unabated, is administration of exogenous ketones, in the form of ketone salts or esters. ${ }^{72}$ Ketone bodies can provide upwards of $40 \%-60 \%$ of energy for the brain during 
times of reduced glucose availability, ${ }^{73,74}$ and unlike glucose metabolism, cerebral uptake and utilisation of ketones is not impaired in mild-to-moderate Alzheimer's disease. ${ }^{75}$ These alternative fuel substrates have proven impressive in the acute clinical setting, with many patients exhibiting rapid and noticeable improvement in cognition, but again, ApoE4 carriers generally do not respond as well as non-carriers, and in some cases, do not respond at all. ${ }^{76,77,78}$

A strong body of evidence supports the use of very low carbohydrate or ketogenic diets to improve type 2 diabetes, insulin sensitivity and multiple features of metabolic syndrome. ${ }^{79,80,81,82,83}$ Being that this type of nutritional strategy may reduce systemic insulin loads, improve glucose metabolism and allow for sustained levels of at least mild-tomoderate ketonaemia, this may prove more effective than providing central insulin infusions or artificially elevating blood ketones without actively implementing measures to correct the root physiological disturbances at the heart of Alzheimer's disease. Indeed, nutritional ketosis (ketosis induced through dietary carbohydrate restriction) and increased dietary medium-chain triglycerides (typically in the form of coconut oil or isolated MCT oils, which are rapidly metabolised into ketones) have been shown to have beneficial effects in subjects with Alzheimer's and mild cognitive impairment. ${ }^{55,75,84}$ Such studies are limited but positive findings for patient outcomes are promising and should spur additional research interest, particularly in light of the disappointing results of pharmaceutical interventions to date. A multifaceted approach addressing dietary and lifestyle interventions known to have beneficial effects on insulin resistance, wholebody metabolism and fuel partitioning - particularly if implemented at the very earliest signs of impaired cognition, considering that systemic insulin resistance and the reduced cerebral use of glucose may precede the manifestation of overt signs and symptoms of cognitive decline by decades - may be the key to chipping away at Alzheimer's disease, which has proven to be an otherwise insurmountable obstacle. Future research endeavours may prove more fruitful if academic interest, clinical efforts and the required financial resources are channelled towards these highly promising therapeutic avenues.

\section{Acknowledgements Competing interests}

The author declares that she has no financial or personal relationships which may have inappropriately influenced her in writing this article.

\section{References}

1. Eli Lilly and Company. Lilly halts development of semagacestat for Alzheimer's disease based on preliminary results of phase III clinical trials [homepage on the Internet]. 2010 [cited 2016 Jan 23]. Available from: http://newsroom.lilly.com/ releasedetail.cfm?releaseid $=499794$

2. Alzheimer's Association. 2015 Alzheimer's disease facts and figures [homepage on the Internet]. 2015 [cited 2016 Jan 22]. Available from: http://www.alz.org/ facts/overview.asp

3. de la Monte SM. Type 3 diabetes is sporadic Alzheimer's disease: Mini review. Eur Neuropsychopharmacol. 2014;24(12):1954-1960. http://dx.doi.org/10.1016/j. euroneuro.2014.06.008
4. Narasimhan K, Govindasamy M, Gauthaman K, et al. Diabetes of the brain: Computational approaches and interventional strategies. CNS Neurol Disord Drug Targets. 2014;13(3):408-417. http://dx.doi.org/10.2174/18715273113126660156

5. Steen E, Terry BM, Rivera EJ, et al. Impaired insulin and insulin-like growth factor expression and signaling mechanisms in Alzheimer's disease - Is this type 3 diabetes? J Alzheimers Dis. 2005;7(1):63-80.

6. De Felice FG, Lourenco MV, Ferreira ST. How does brain insulin resistance develop in Alzheimer's disease? Alzheimers Dement. 2014;10(1 Suppl):S26-S32. http:// dx.doi.org/10.1016/j.jalz.2013.12.004

7. de la Monte SM. Metabolic derangements mediate cognitive impairment and Alzheimer's disease: Role of peripheral insulin resistance diseases. Panminerva Med. 2012;54(3):171-178.

8. de la Monte SM. Brain insulin resistance and deficiency as therapeutic tin Alzheimer's disease. Curr Alzheimer Res. 2012;9(1):35-66. http://dx.doi. org/10.2174/156720512799015037

9. de la Monte SM. Contributions of brain insulin resistance and deficiency in amyloid-related neurodegeneration in Alzheimer's disease. Drugs. 2012;72(1) 49-66. http://dx.doi.org/10.2165/11597760-000000000-00000

10. Dineley KT, Jahrling JB, Denner L. Insulin resistance in Alzheimer's disease. Neurobiol Dis. 2014;72PA:92-103. http://dx.doi.org/10.1016/j.nbd.2014.09.001

11. Morgen K, Frölich L. The metabolism hypothesis of Alzheimer's disease: From the concept of central insulin resistance and associated consequences to insulin therapy. J Neural Transm (Vienna). 2015;122(4):499-504. http://dx.doi. org/10.1007/s00702-015-1377-5

12. Neumann KF, Rojo L, Navarrete LP, Farías G, Reyes $P$, Maccioni RB. Insulin resistance and Alzheimer's disease: Molecular links \& clinical implications. Curr Alzheimer Res. 2008;5(5):438-447. http://dx.doi.org/10.2174/ 156720508785908919

13. Willette AA, Bendlin BB, Starks EJ, et al. Association of insulin resistance with cerebral glucose uptake in late middle-aged adults at risk for Alzheimer disease. JAMA Neurol. 2015;72(9):1013-1020. http://dx.doi.org/10.1001/jamaneurol. 2015.0613.

14. Willette AA, Modanlo N, Kapogiannis D, et al. Insulin resistance predicts medial temporal hypermetabolism in mild cognitive impairment conversion to Alzheimer disease. Diabetes. 2015;64(6):1933-1940. http://dx.doi.org/10.2337/db14-1507

15. Luchsinger JA, Tang MX, Shea S, Mayeux R. Hyperinsulinemia and risk of Alzheimer disease. Neurology. 2004;63(7):1187-1192. http://dx.doi.org/10.1212/01. disease. Neurology. 2004,6
WNL.0000140292.04932.87

16. Young SE, Mainous AG 3rd, Carnemolla M. Hyperinsulinemia and cognitive decline in a middle-aged cohort. Diab Care. 2006;29(12):2688-2693. http://dx.doi. org/10.2337/dc06-0915

17. Kraft J, Wehrmacher WH. Diabetes - A silent disorder. Compr Ther. 2009; 35(3-4):155-159.

18. Kraft JR. Diabetes epidemic \& you. Bloomington, IN: Trafford Publishing; 2008.

19. Folch J, Pedrós I, Patraca I, et al. Metabolic basis of sporadic Alzeimer's disease: Role of hormones related to energy metabolism. Curr Pharm Des. 2013;19(38):6739-6748. http://dx.doi.org/10.2174/13816128113199990612

20. Frisardi V, Solfrizzi V, Capurso $C$, et al. Is insulin resistant brain state a central feature of the metabolic-cognitive syndrome? J Alzheimers Dis. 2010;21(1): 57-63.

21. Frisardi V, Solfrizzi V, Seripa D, et al. Metabolic-cognitive syndrome: A cross-talk between metabolic syndrome and Alzheimer's disease. Ageing Res Rev. 2010;9(4):399-417. http://dx.doi.org/10.1016/j.arr.2010.04.007

22. Schubert M, Gautam D, Surjo D, et al. Role for neuronal insulin resistance in neurodegenerative diseases. Proc Natl Acad Sci U S A. 2004;101(9):3100-3105. http://dx.doi.org/10.1073/pnas.0308724101

23. Chen Z, Zhong C. Decoding Alzheimer's disease from perturbed cerebral glucose metabolism: Implications for diagnostic and therapeutic strategies. Pros Neurobiol. 2013;108:21-43. http://dx.doi.org/10.1016/j.pneurobio.2013.06.004

24. Stokin GB, Goldstein LS. Axonal transport and Alzheimer's disease. Annu Rev Biochem. 2006;75:607-627. http://dx.doi.org/10.1146/annurev.biochem.75. 103004.142637

25. Fukuyama $H$, Ogawa $M$, Yamauchi $H$, et al. Altered cerebral energy metabolism in Alzheimer's disease: A PET study. J Nucl Med. 1994;35(1):1-6.

26. Caselli RJ, Reiman EM. Characterizing the preclinical stages of Alzheimer's disease and the prospect of presymptomatic intervention. J Alzheimer's Dis. 2013;33(Suppl. 1):S405-S416.

27. Reiman EM, Chen K, Alexander GE, et al. Functional brain abnormalities in young adults at genetic risk for late-onset Alzheimer's dementia. Proc Natl Acad Sc U S A. 2004;101(1):284-289. http://dx.doi.org/10.1073/pnas.2635903100

28. Mosconi L, De Santi S, Li J, et al. Hippocampal hypometabolism predicts cognitive decline from normal aging. Neurobiol Aging. 2008;29(5):676-692. http://dx.doi. org/10.1016/j.neurobiolaging.2006.12.008

29. Mosconi L. Brain glucose metabolism in the early and specific diagnosis of Alzheimer's disease. FDG-PET studies in $\mathrm{MCl}$ and AD. Eur J Nucl Med Mol Imaging. 2005;32(4):486-510. http://dx.doi.org/10.1007/s00259-005-1762-7

30. Plum L, Schubert $M$, Brüning JC. The role of insulin receptor signaling in the brain. Trends Endocrinol Metab. 2005;16(2):59-65. http://dx.doi.org/10.1016/j. tem.2005.01.008

31. Woods SC, Seeley RJ, Baskin DG, Schwartz MW. Insulin and the bloodbrain barrier. Curr Pharm Des. 2003;9(10):795-800. http://dx.doi.org/10.2174/ 1381612033455323 
32. Blázquez E, Velázquez E, Hurtado-Carneiro V, Ruiz-Albusac JM. Insulin in the brain: Its pathophysiological implications for states related with central insulin resistance, type 2 diabetes and Alzheimer's disease. Front Endocrinol. 2014;5:161. http://dx.doi.org/10.3389/fendo.2014.00161

33. Craft S, Peskind E, Schwartz MW, et al. Cerebrospinal fluid and plasma insulin levels in Alzheimer's disease: Relationship to severity of dementia and apolipoprotein E genotype. Neurology. 1998;50(1):164-168. http://dx.doi. org/10.1212/WNL.50.1.164

34. Baker LD, Cross D, Minoshima S, Belongia D, Watson GS, Craft S. Insulin resistance is associated with Alzheimer-like reductions in regional cerebral glucose metabolism for cognitively normal adults with pre-diabetes or early type 2 diabetes. Arch Neurol. 2011;68(1):51-57. http://dx.doi.org/10.1001/archneurol. diabetes.

35. Li YM, Dickson DW. Enhanced binding of advanced glycation endproducts (AGE) by the ApoE4 isoform links the mechanism of plaque deposition in Alzheimer's disease. Neurosci Lett. 1997;226(3):155-158. http://dx.doi.org/10.1016/S03043940(97)00266-8

36. Cook DG, Leverenz JB, McMillan PJ, et al. Reduced hippocampal insulin-degrading enzyme in late-onset Alzheimer's disease is associated with the apolipoprotein E- $\varepsilon 4$ allele. Am J Pathol. 2003;162(1):313-319. http://dx.doi.org/10.1016/S0002$9440(10) 63822-9$

37. Xie L, Helmerhorst E, Taddei K, et al. Alzheimer's beta-amyloid peptides compete for insulin binding to the insulin receptor. J Neurosci. 2002;22(10):RC221.

38. Qiu WQ, Walsh DM, Ye Z, Vekrellis K, et al. Insulin-degrading enzyme regulates extracellular levels of amyloid beta-protein by degradation. I Biol Chem. 1998;273(49):32730-32738. http://dx.doi.org/10.1074/jbc.273.49.32730

39. Schmechel DE, Saunders AM, Strittmatter WJ, et al. Increased amyloid beta-peptide deposition in cerebral cortex as a consequence of apolipoprotein genotype in late-onset Alzheimer disease. Proc Natl Acad Sci U S A. 1993;90(20):9649-9653. http://dx.doi.org/10.1073/pnas.90.20.9649

40. Qiu W, Folstein $M$. Insulin, insulin-degrading enzyme and amyloid- $\beta$ peptide in Alzheimer's disease: Review and hypothesis. Neuro Biol Aging. 2006;27:190-198. $\mathrm{http}: / / \mathrm{dx}$.doi.org/10.1016/j.neurobiolaging.2005.01.004

41. Henderson S. High carbohydrate diets and Alzheimer's disease. Med Hypotheses. 2004;62:689-700. http://dx.doi.org/10.1016/j.mehy.2003.11.028

42. Seneff S, Wainwright G, Mascitelli L. Nutrition and Alzheimer's disease: The detrimental role of a high carbohydrate diet. Eur J Intern Med. 2011;22(2):134detrimental role of a high carbohydrate diet. Eur 1 .

43. Spreadbury I. Comparison with ancestral diets suggests dense a cellular carbohydrates promote an inflammatory microbiota, and may be the primary dietary cause of leptin resistance and obesity. Diabetes Metabc Syndr Obes. 2012;5:175-189. http://dx.doi.org/10.2147/DMSO.S33473

44. Chaput JP, McNeil J, Després JP, Bouchard C, Tremblay A. Short sleep duration as a risk factor for the development of the metabolic syndrome in adults. Prev Med. 2013;57(6):872-877. http://dx.doi.org/10.1016/j.ypmed.2013.09.022

45. Knutson KL, Spiegel K, Penev P, Van Cauter E. The metabolic consequences of sleep deprivation. Sleep Med Rev. 2007;11(3):163-178. http://dx.doi.org/ 10.1016/j.smrv.2007.01.002

46. Reutrakul S, Van Cauter E. Interactions between sleep, circadian function, and glucose metabolism: Implications for risk and severity of diabetes. Ann N Y Acad Sci. 2014;1311:151-173. http://dx.doi.org/10.1111/nyas.12355

47. Musiek ES, Xiong DD, Holtzman DM. Sleep, circadian rhythms, and the pathogenesis of Alzheimer disease. Exp Mol Med. 2015;47(3):e148. http://dx.doi org/10.1038/emm.2014.121

48. Lucey BP, Bateman RJ. Amyloid- $\beta$ diurnal pattern: Possible role of sleep in Alzheimer's disease pathogenesis. Neurobiol Aging. 2014;35(Suppl. 2):S29-S34. $\mathrm{http}: / / \mathrm{dx}$.doi.org/10.1016/j.neurobiolaging.2014.03.035

49. Bu X-L, Liu Y-H, Wang Q-H, et al. Serum amyloid-beta levels are increased in patients with obstructive sleep apnea syndrome. Sci Rep. 2015;5:13917. http:// dx.doi.org/10.1038/srep13917

50. Spira AP, Gamaldo AA, An Y, et al. Self-reported sleep and $\beta$-amyloid deposition in community-dwelling older adults. JAMA Neurol. 2013;70(12):1537-1543. http:// dx.doi.org/10.1001/jamaneurol.2013.4258

51. Xie L, Kang $\mathrm{H}, \mathrm{Xu} \mathrm{Q}$, et al. Sleep drives metabolite clearance from the adult brain Science (New York, NY). 2013;342(6156):373-377. http://dx.doi.org/10.1126/ science.1241224

52. Castello M, Soriano S. On the origin of Alzheimer's disease. Trials and tribulations of the amyloid hypothesis. Ageing Res Rev. 2014;13:10-12. http://dx.doi. org/10.1016/j.arr.2013.10.001

53. Castello M, Jeppson J, Soriano S. Moving beyond anti-amyloid therapy for the prevention and treatment of Alzheimer's disease. BMC Neurol. 2014;14:169. http://dx.doi.org/10.1186/s12883-014-0169-0

54. Kamboh M. Apolipoprotein E polymorphism and susceptibility to Alzheimer's disease. Hum Biol. 1995;67(2):195-215

55. Krikorian R, Shidler M, Dangelo K, et al. Dietary ketosis enhances memory in mild cognitive impairment. Neurobiol Aging. 2012;33:425e19-425e27.

56. Lane RM, Farlow MR. Lipid homeostasis and apolipoprotein E in the development and progression of Alzheimer's disease. J Lipid Res. 2005;46(5):949-968. http:// dx.doi.org/10.1194/jlr.M400486-JLR200

57. Corbo RM, Scacchi R. Apolipoprotein E (APOE) allele distribution in the world. Is APOE*4 a 'thrifty' allele? Ann Hum Genet. 1999;63(4):301-310. http://dx.doi. org/10.1046/j.1469-1809.1999.6340301.x
58. Strittmatter W, Roses A. Apolipoprotein E and Alzheimer's disease. Annu Rev Neurosci. 1996;19:53-77. http://dx.doi.org/10.1146/annurev.ne.19.030196. 000413

59. Cordain, L Eaton SB, Sebastian A, et al. Origins and evolution of the Western diet Health implications for the 21st century. Am J Clin Nutr. 2005;81:341-354.

60. Eaton SB, Cordain L. Evolutionary aspects of diet: Old genes, new fuels. World Rev Nutr Diet. 1997;81:26-37. http://dx.doi.org/10.1159/000059599

61. Correia S, Santos E, Carvalho C, et al. Insulin signaling, glucose metabolism and mitochondria: Major players in Alzheimer's disease and diabetes interrelation. Brain Res. 2012;1441:64-78. http://dx.doi.org/10.1016/j.brainres.2011.12.063

62. Moreira $P$, Santos $M$, Seica $R$, et al. Brain mitochondrial dysfunction as a link between Alzheimer's disease and diabetes. J Neurol Sci. 2007;257(1-2):206-214. http://dx.doi.org/10.1016/j.jns.2007.01.017

63. Vanltallie TB. Biomarkers, ketone bodies, and the prevention of Alzheimer's disease. Metabolism. 2015;64(3 Suppl. 1):S51-S57. http://dx.doi.org/10.1016/j. metabol.2014.10.033

64. Bredesen DE. Reversal of cognitive decline: A novel therapeutic program. Aging (Albany NY). 2014;6(9):707-717. http://dx.doi.org/10.18632/aging.100690

65. Baker LD, Frank LL, Foster-Schubert K, et al. Aerobic exercise improves cognition for older adults with glucose intolerance, a risk factor for Alzheimer's disease. J Alzheimer's Dis. 2010;22(2):569-579.

66. Coelho FG, Vital TM, Stein AM, et al. Acute aerobic exercise increases brain derived neurotrophic factor levels in elderly with Alzheimer's disease. J Alzheimers Dis. 2014;39(2):401-408.

67. Cunnane S, Nugent $S$, Roy M, et al. Brain fuel metabolism, aging and Alzheimer's disease. Nutrition. 2011;27(1):3-20. http://dx.doi.org/10.1016/j.nut.2010.07.021

68. Irrcher I, Adhihetty PJ, Joseph AM, et al. Regulation of mitochondrial biogenesis in muscle by endurance exercise. Sports Med. 2003;33(11):783-793. http://dx.doi. org/10.2165/00007256-200333110-00001

69. Prior SJ, Blumenthal JB, Katzel LI, Goldberg AP, Ryan AS. Increased skeletal muscle capillarization after aerobic exercise training and weight loss improves insulin sensitivity in adults with IGT. Diab Care. 2014;37(5):1469-1475. http://dx.doi. sensitivity in adults with
org/10.2337/dc13-2358

70. Reger MA, Watson GS, Frey WH 2nd, et al. Effects of intranasal insulin on cognition in memory-impaired older adults: Modulation by APOE genotype. Neurobio Aging. 2006;27(3):451-458. http://dx.doi.org/10.1016/j.neurobiolaging.2005. 03.016

71. Reger MA, Watson GS, Green PS, et al. Intranasal insulin administration dosedependently modulates verbal memory and plasma $\beta$-amyloid in memoryimpaired older adults. J Alzheimers Dis. 2008;13(3):323-331.

72. Newport MT, Vanltallie TB, Kashiwaya Y, King MT, Veech RL. A new way to produce hyperketonemia: Use of ketone ester in a case of Alzheimer's. Alzheimers Dement. 2015;11(1):99-103. http://dx.doi.org/10.1016/j.jalz.2014.01.006

73. Vanltallie T, Nufert T. Ketones: Metabolism's ugly duckling. Nutr Rev. 2003;61(10):327-341. http://dx.doi.org/10.1301/nr.2003.oct.327-341

74. Veech R. The therapeutic implications of ketone bodies: The effects of ketone bodies in pathological conditions: Ketosis, ketogenic diet, redox states, insulin resistance, and mitochondrial metabolism. Prostaglandins Leukot Essent Fatty Acids. 2003;70(3):309-319. http://dx.doi.org/10.1016/j.plefa.2003.09.007

75. Cunnane SC, Courchesne-Loyer A, Vandenberghe $C$, et al. Can ketones help rescue brain fuel supply in later life? Implications for cognitive health during aging and brain fuel supply in later life? Implications for cognitive health during aging and
the treatment of Alzheimer's disease. Front Mol Neurosci. 2016:9:53. http://dx. the treatment of Alzheimer's disease.
doi.org/10.3389/fnmol.2016.00053

76. Henderson S. Ketone bodies as a therapeutic for Alzheimer's disease. Neurotherapeutics. 2008;5(3):470-480. http://dx.doi.org/10.1016/j.nurt.2008. 05.004

77. Henderson ST, Vogel JL, Barr LJ, et al.. Study of the ketogenic agent AC- 1202 in mild to moderate Alzheimer's disease: A randomized, double-blind, placebocontrolled, multicenter trial. Nutr Metab (Lond). 2009;6:31. http://dx.doi. org/10.1186/1743-7075-6-31

78. Reger MA, Henderson ST, Hale C, et al. Effects of beta-hydroxybutyrate on cognition in memory-impaired adults. Neurobiol Aging. 2004;25(3):311-314. http://dx.doi.org/10.1016/S0197-4580(03)00087-3

79. Accurso A, Bernstein RK, Dahlqvist A, et al. Dietary carbohydrate restriction in type 2 diabetes mellitus and metabolic syndrome: Time for a critical appraisal. Nutr Metab. 2008;5:9. http://dx.doi.org/10.1186/1743-7075-5-9

80. Feinman RD, Pogozelski WK, Astrup A, et al. Dietary carbohydrate restriction as the first approach in diabetes management: Critical review and evidence base. Nutrition. 2015;31(1):1-13. http://dx.doi.org/10.1016/j.nut.2014.06.011

81. Volek JS, Fernandez ML, Feinman RD, Phinney SD. Dietary carbohydrate restriction induces a unique metabolic state positively affecting atherogenic dyslipidemia, fatty acid partitioning, and metabolic syndrome. Prog Lipid Res. 2008;47(5): 307-318. http://dx.doi.org/10.1016/j.plipres.2008.02.003

82. Westman EC, Feinman RD, Mavropoulos JC, et al. Low-carbohydrate nutrition and metabolism. Am J Clin Nutr. 2007;86(2):276-284.

83. Yancy WS, Foy M, Chalecki AM, Vernon MC, Westman EC. A low-carbohydrate, ketogenic diet to treat type 2 diabetes. Nutr Metab. 2005;2:34. http://dx.doi. org/10.1186/1743-7075-2-34

84. Rebello CJ, Keller JN, Liu AG, Johnson WD, Greenway FL. Pilot feasibility and safety study examining the effect of medium chain triglyceride supplementation in subjects with mild cognitive impairment: A randomized controlled trial. BBA Clin. 2015;3:123-125. http://dx.doi.org/10.1016/j.bbacli.2015.01.001 